\title{
ATIVIDADE ALELOPÁTICA DE EXTRATO AQUOSO DE Croton glandulosus L. NA GERMINAÇÃO E NO DESENVOLVIMENTO INICIAL DE ALFACE
}

Teli Cristiane Briekowiec KREMER ${ }^{1}$

Oscar Mitsuo YAMASHITA ${ }^{2}$

Ricardo Adriano FELITO ${ }^{1}$

Aureane Cristina Teixeira FERREIRA ${ }^{1}$

Cleonete Ferreira de ARAÚJO ${ }^{1}$

\begin{abstract}
${ }^{1}$ Mestrandos Programa de Pós-graduação em Biodiversidade e Agroecossistemas Amazônicos da Universidade do Estado de Mato Grosso, Campus de Alta Floresta, telicristiane@gmail.com; ricardofelito@hotmail.com; aureaneferreira@hotmail.com; cleonetearaujo@hotmail.com; ${ }^{2}$ Prof. Programa de Pós-graduação em Biodiversidade e Agroecossistemas Amazônicos da Universidade do Estado de Mato Grosso, yama@unemat.br
\end{abstract}

Recebido em: 13/11/2015 - Aprovado em: 25/05/2016 - Disponibilizado em: 30/07/2016

\begin{abstract}
RESUMO: Objetivou-se avaliar o efeito alelopático das partes: raízes, caule, folhas e frutos de Croton glandulosus L. em bioensaios com sementes de alface (Lactuca sativa). Para isso, foram preparados extratos aquosos das partes da planta (raiz, caule, fruto e folha) nas concentrações $0,10,20$ e $40 \%(\mathrm{p} / \mathrm{v})$, em esquema fatorial 4 x 4, com quatro repetições de 50 sementes. Foram utilizadas caixas tipo gerbox forradas com papel Germitest e umedecidas com os extratos, sendo estas mantidas em câmara de germinação à temperatura constante de $25^{\circ} \mathrm{C}$ e fotoperíodo de 12 horas por sete dias. Foram determinados: germinação, índice de velocidade de germinação, massa de matéria seca, o comprimento radicular e da parte aérea das plântulas. Observou-se que as plântulas foram afetadas na presença de extratos aquosos de raízes e folhas secas nas concentrações 20 e $40 \%$.
\end{abstract}

Palavras-chave: Alelopatia. Extratos aquosos. Planta daninha. Germinabilidade. Gervão.

\section{ALLELOPATHIC ACTIVITY OF AQUEOUS EXTRACT OF Croton glandulosus L. ON GERMINATION AND INITIAL DEVELOPMENT OF LETTUCE}

\begin{abstract}
We aimed to evaluate the allelopathic effect of parts: roots, stalk, leaves and fruits of Croton glandulosus L. in bioassays using seeds of lettuce (Lactuca sativa). For this, we prepared aqueous extracts of plant's parts (root, stalk, fruit and leaf) at concentrations $0,10,20$ and $40 \%(\mathrm{w} / \mathrm{v})$ in a factorial scheme $4 \times 4$, with four replications of 50 seeds. We used boxes gerbox lined with Germitest paper and moistened with the extracts, which were kept in a germination chamber at a constant temperature of $25^{\circ} \mathrm{C}$ and photoperiod of 12 hours per seven days. We determined: germination, germination speed index, dry matter, root length and length shoot seedling. We observed that the seedlings were affected in the presence of aqueous root extracts and leaves dried at concentrations 20 and $40 \%$.
\end{abstract}

Keywords: Allelopathy. Aqueous extracts. Weed. Germinability. Gervão. 


\section{INTRODUÇÃO}

A presença de plantas daninhas nas pastagens é um dos principais problemas enfrentados pelos pecuaristas e agricultores, que limitam a capacidade produtiva das áreas com essa atividade (PAULINO et al., 2012; VENDRAME et al., 2014). A maioria destas plantas daninhas apresentam algum potencial alelopático e consequentemente interferem no desenvolvimento normal das forrageiras, causando modificações na população das demais plantas. Assim, passam a predominar as espécies que melhor se adaptam àquelas condições (RODRIGUES et al., 2012).

Essas espécies são demasiadamente agressivas e, por apresentarem elevada capacidade de produção de sementes viáveis e adaptações especiais para disseminá-las, têm a sua dispersão facilitada, ocupando a área rapidamente. São plantas que também possuem elevada capacidade de competição e atributos específicos que asseguram a perpetuação, tais como dormência, germinação desuniforme e potencial alelopático (OLIVEIRA et al., 2012).

Algumas pesquisas evidenciam a necessidade de avaliação da ação alelopática de plantas daninhas em áreas de pastagem. A espécie de estudo Croton grandulosus L. popularmente conhecida como gervão, gervão-branco, malva-vermelha e velame, é subarbustiva anual que se desenvolve em todo o País, vegeta em ambientes antropizados ou de solo naturalmente pobre em áreas bastante abertas. Ocorre como invasora de culturas, que apesar dos efeitos benéficos de sua presença por atrair insetos predadores, é combatida. Produz flores masculinas brancas e femininas esverdeadas, que fornecem recursos alimentares para abelhas durante todo o ano. A dispersão ocorre por deiscência explosiva dos frutos. Apresenta caule verde com pigmentação ferrugínea, bastante ramificado. Folhas opostas cruzadas, simples e pecioladas (MOREIRA \& BRAGANÇA, 2011).

Pesquisas sobre atividade alelopática da espécie Croton glandulosus ainda é incipiente no Brasil, considerando-se a extensão territorial e a diversidade florística, assim não são encontradas informações relativas á capacidade desta em interferir negativamente em outras plantas. Em vista disto, a ampliação desse conhecimento para as pesquisas na área é de suma importância servindo como instrumento de manejo ecológico ao intenso uso de herbicidas no meio ambiente. $\mathrm{O}$ presente estudo teve como objetivo avaliar o potencial alelopático de Croton glandulosus na germinação e crescimento inicial de alface (Lactuca sativa L.) por meio de bioensaio laboratorial.

\section{MATERIAL E MÉTODOS}

A coleta do material vegetal utilizado para a obtenção do extrato foi realizada em uma área de pastagem localizada no 
município de Alta Floresta. Após a coleta, o material foi lavado sob água corrente e separadas as partes: raiz, caule, folhas $\mathrm{e}$ frutos. Em seguida, os materiais foram armazenados em sacos de papel kraft devidamente identificados e levados para a secagem em estufa de circulação forçada de ar por 96 horas à temperatura de $65{ }^{\circ} \mathrm{C}$, posteriormente os materiais foram triturados. Como planta teste, utilizaram-se sementes de alface (Lactuca sativa L. cv. Veneranda) adquiridas no comércio local e cuja germinação foi previamente testada.

Para o estudo do efeito alelopático, foram utilizados os extratos aquosos da raiz, caule, folha, frutos dissolvidos em água destilada nas concentrações de $0,10,20$ e 40 $\mathrm{mg} \mathrm{mL}^{-1}$, organizado em esquema fatorial $4 \mathrm{x}$ 4, sendo quatro partes da planta e quatro concentrações, com quatro repetições.

A obtenção do extrato aquoso foi realizada por infusão, adicionado água quente $\left(85^{\circ} \mathrm{C}\right)$, na proporção de $1: 25(\mathrm{p} / \mathrm{v})$, por um período de 15 minutos. A solução foi filtrada e preparadas as demais diluições $(0,10,20$ e $40 \mathrm{mg} \mathrm{mL}^{-1}$ ).

O ensaio de germinação foi realizado em câmara de germinação do tipo BOD com fotoperíodo de 12 horas de luz/escuro e temperatura constante de $25{ }^{\circ} \mathrm{C}$, conforme recomendação de BRASIL (2009). As unidades experimentais foram constituídas por caixas de gerbox transparente, revestidas com duas folhas de papel germibox previamente autoclavadas a $120^{\circ} \mathrm{C}$ por 40 minutos. Posteriormente, foram distribuídas 50 sementes de alface em cada parcela, com quatro repetições por tratamento.

As caixas foram dispostas dentro da BOD em delineamento inteiramente casualizado. Foi determinada, após sete dias, a germinação das sementes. A determinação do índice de velocidade de germinação (IVG) das sementes foi realizada conforme Maguire (1962). Ao final do ensaio, foram retiradas todas as plântulas de cada parcela foram secadas em estufa de circulação forçada de ar por 72 horas a $65{ }^{\circ} \mathrm{C}$, para determinação da massa de matéria seca das plântulas.

A significância do efeito dos tratamentos foi determinada por meio do Teste F, sendo as médias do fator "partes da planta" comparadas por meio do Teste de Tukey. Para o fator "concentrações" foram ajustadas regressões polinomiais.

\section{RESULTADOS E DISCUSSÃO}

O desempenho germinativo das sementes de alface foi influenciado pela interação entre parte de planta e concentração de extrato aquoso de Croton glandulosus ( $\mathrm{p}<$ $0,05)$ para germinação e IVG, mas não para massa seca de plântulas (Tabela 1).

As maiores concentrações (20 e 40\%) de extrato da raiz prejudicaram a germinação das sementes de alface (Tabela 2 e Figura 1). Essa reduzida germinação configura-se forte 
indicativo de concentração de aleloquímicos na raiz, demonstrando característica de potencial alelopático desta planta daninha, influenciando negativamente esta variável à medida que a concentração do extrato era aumentada.

Esses resultados são semelhantes aos observados por FORMAGIO et al. (2012) e GRISI et al. (2013) que também verificaram que o extrato radicular de Croton glandulosus provocou um efeito inibitório mais acentuado em altas concentrações. No processo germinativo, as sementes que ficam em contato com a solução do substrato, podem sofrer o efeito da penetração de algumas substâncias alelopáticas, juntamente com a água de hidratação, capazes de inibir ou retardar a multiplicação ou crescimento das células, podendo também retardar a germinação (GONZALEZ et al., 2002; RITTER et al., 2014), fato verificado no presente trabalho.

O extrato da raiz normalmente apresenta grande quantidade de metabólitos secundários com forte poder inibitório, pois a raiz é o principal local de entrada de nutrientes e água e, por se encontrar no solo, está mais suscetível ao ataque de microorganismos e aleloquímicos de outras plantas próximas que estão se defendendo ou até mesmo atacando, buscando condições apropriadas para seu desenvolvimento (REZENDE et al., 2011; KHALIQ et al., 2013; SILVEIRA et al., 2014).
Tabela 1. Quadrado médio e coeficiente de variação (C.V.) para porcentagem de germinação $(\% \mathrm{G})$, índice de velocidade de germinação (IVG) e massa seca de plântula (MS) de alface (Lactuca sativa), submetidas a concentrações $(\mathrm{p} / \mathrm{v})$ de extratos de Croton glandulosus L. Alta Floresta - MT, 2015.

\begin{tabular}{lccc}
\hline & $\% \mathrm{G}$ & $\mathrm{IVG}$ & $\mathrm{MS}$ \\
\hline Parte (P) & $49,333^{* *}$ & $525,866^{* *}$ & $9,021^{* *}$ \\
Concentração & $85,500^{* *}$ & $1659,009^{* *}$ & $7,438^{* *}$ \\
(C) & & & \\
P*C & $25,944^{* *}$ & $79,126^{* *}$ & $2,507 \mathrm{~ns}$ \\
Resíduo & 10,292 & 24,899 & 1,417 \\
\hline C.V. (\%) & 3,35 & 13,48 & 15,80 \\
\hline ns = não significativo pelo teste F. ${ }^{* *}=$ significativo a \\
5\% de probabilidade pelo teste F
\end{tabular}

Extratos de caule e fruto não promoveram redução na germinação das sementes, independentemente da concentração testada. Entretanto, extratos produzidos a partir das folhas demonstraram efeito inibitório na germinação das sementes de alface, verificando-se uma redução que atingiu $8 \%$ na concentração de $20 \%$. CAPOBIANGO et al. (2009) e DE CONTI et al. (2011) também relatam resultados semelhantes aos obtidos neste estudo onde os extratos de folhas secas de Casearia sylvestris provocaram efeito alelopático reducional alface. Além da alta concentração de aleloquímicos presente na raiz, pela intensa mobilização via xilema e floema, é possível observar também concentrações relativamente altas em outras partes da planta em estudo, como verificado na pesquisa (Tabela 2), que a atividade alelopática inibindo a germinação 
foi constatada nos extratos de caule e frutos, porém em menores proporções.

Tabela 2. Germinação de sementes de alface (Lactuca sativa), submetidas a concentrações $(\mathrm{p} / \mathrm{v})$ de extratos de Croton glandulosus L. Alta Floresta - MT, 2015.

\begin{tabular}{ccccc}
\hline Concentraç & \multicolumn{4}{c}{ Parte da planta } \\
\cline { 2 - 5 } ão $(\%)$ & Raiz & Caule & Folha & Fruto \\
\hline 0 & $99,0 \mathrm{Aa}$ & $97,5 \mathrm{Aa}$ & $98,0 \mathrm{Aa}$ & $98,0 \mathrm{Aa}$ \\
10 & $98,0 \mathrm{Aa}$ & $98,0 \mathrm{Aa}$ & $96,0 \mathrm{Aab}$ & $97,0 \mathrm{Aa}$ \\
20 & $90,5 \mathrm{Bb}$ & $97,0 \mathrm{Aa}$ & $90,0 \mathrm{Bb}$ & $95,5 \mathrm{Aba}$ \\
40 & $88,5 \mathrm{Bb}$ & $97,5 \mathrm{Aa}$ & $94,0 \mathrm{ABab}$ & $97,5 \mathrm{Aa}$ \\
\hline
\end{tabular}

CV (\%)

*Médias seguidas de mesma letra maiúscula na linha e minúscula na coluna não diferem entre si pelo teste de Tukey a $5 \%$ de probabilidade.

Para a variável IVG, observou-se interação entre parte da planta e concentração do extrato (Tabela 3). Todas as partes de croton (raiz, caule, folha e fruto) promoveram decréscimo no IVG à medida que a concentração aumentava (Figura 2). Resultados semelhantes foram relatados por GRISPI et al. (2013), em que apesar da concentração de Sapindus saponaria não ter interferido na germinação, o IVG foi significativamente reduzido. A velocidade de germinação das sementes de alface foi afetada negativamente, pois os aleloquímicos presentes na espécie daninha em estudo reduziram a capacidade germinativa e consequentemente a velocidade em que estas poderiam emergir, diferenciando significativamente da testemunha.

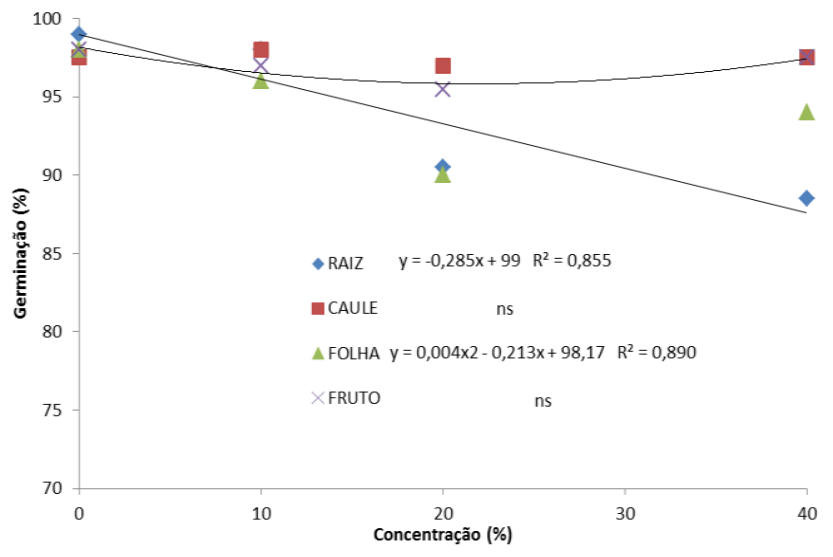

Figura 1. Germinação de sementes de alface, submetidas a diferentes doses de extrato aquoso de Croton glandulosus. Alta Floresta/MT, 2015.

Muitas vezes, o efeito aleloquímico provocado pelos metabólitos secundários liberados pela planta se manifesta muito mais sobre a velocidade de germinação dos diásporos ou sobre outra característica do processo germinativo do que sobre a germinação (FERREIRA \& AQUILA, 2000; JABRAN, et al., 2010). O tempo de germinação e a velocidade desse processo são fatores muito importantes para a sobrevivência das plântulas, refletindo no desenvolvimento destas (RITTER et al., 2014). Sementes que germinam mais lentamente podem dar origem a plântulas com tamanho reduzido e podem consequentemente ser mais suscetíveis a estresses e predação, havendo menor chance na competição por recursos (DADKHAH \& ASAADI, 2010; OLIVEIRA et al., 2012). 
Tabela 3. Índice de velocidade de germinação (IVG) de sementes de alface (Lactuca sativa), submetidas à concentrações $(\mathrm{p} / \mathrm{v})$ de extratos de Croton glandulosus L. Alta Floresta - MT, 2015.

\begin{tabular}{ccccc}
\hline Concentra & \multicolumn{4}{c}{ Parte da planta } \\
\cline { 2 - 5 } ção (\%) & Raiz & Caule & Folha & Fruto \\
\hline 0 & $47,00 \mathrm{Aa}$ & $48,46 \mathrm{Aa}$ & $48,13 \mathrm{Aa}$ & $47,33 \mathrm{Aa}$ \\
10 & $38,79 \mathrm{Aba}$ & $48,00 \mathrm{Aa}$ & $36,90 \mathrm{Bb}$ & $45,08 \mathrm{Aba}$ \\
20 & $23,79 \mathrm{Cb}$ & $45,40 \mathrm{Aab}$ & $30,21 \mathrm{BCb}$ & $35,36 \mathrm{Bb}$ \\
40 & $19,48 \mathrm{Bb}$ & $37,13 \mathrm{Ab}$ & $17,12 \mathrm{Bc}$ & $24,00 \mathrm{Bc}$ \\
\hline
\end{tabular}

$\mathrm{CV}(\%) \quad 13,48$

*Médias seguidas de mesma letra maiúscula na linha e minúscula na coluna não diferem entre si pelo teste de Tukey a $5 \%$ de probabilidade.

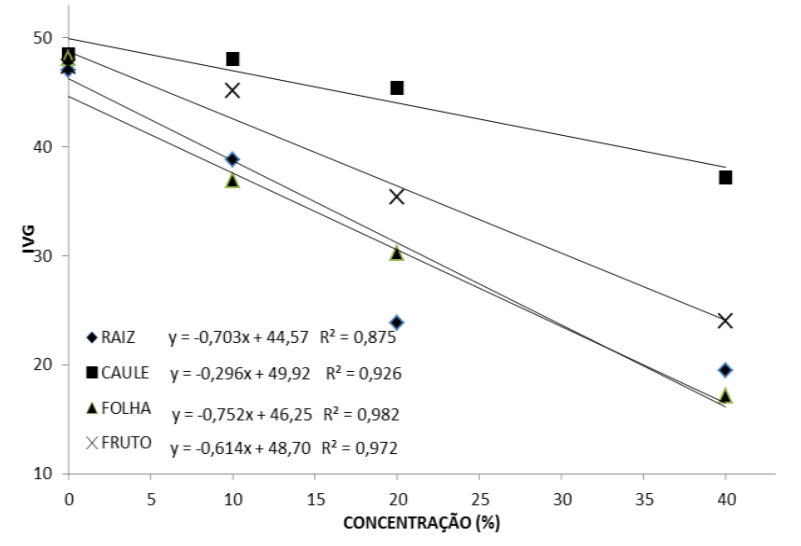

Figura 2. Índice de Velocidade de Germinação (IVG), submetidas a diferentes doses de extrato aquoso de Croton glandulosus. Alta Floresta/MT, 2015.

Para massa de matéria seca de plântulas, não foi verificada interação significativa, sendo que tanto as concentrações como a parte da planta influenciaram nesta variável, de forma isolada $(\mathrm{p}<0,05)$ (Figura 3 e Tabela 4).

O menor valor de massa de matéria seca foi observado na testemunha, e que para a concentração de $20 \%$ observou-se maior valor e, a partir da qual houve um decréscimo.
Observa-se que a presença de extratos de cróton promoveu o desenvolvimento das plântulas que germinaram, apesar de terem reduzido esta última variável. Das plântulas que se desenvolveram, estas conseguiram capturar material dissolvido no substrato umedecido com os extratos, que foram importantes para seu acumulo de matéria seca. Entretanto, percebe-se que, a partir de $20 \%$ de extrato, houve uma tendência de redução na massa de matéria seca das plântulas.

Aparentemente, houve um estímulo nesta variável, já a partir da menor concentração testada. $\mathrm{O}$ conceito de alelopatia envolve efeitos de prejuízos, mas também de estímulos. De maneira similar ao presente estudo, KNOX et al. (2010) afirmam que os compostos secundários das plantas podem ser continuamente sintetizados e degradados nas células, com finalidades específicas, que podem entre outras, promover o acúmulo de substâncias, causando uma ação estimulatória, até certa concentração e, a partir daí, novamente provocar efeitos deletérios.

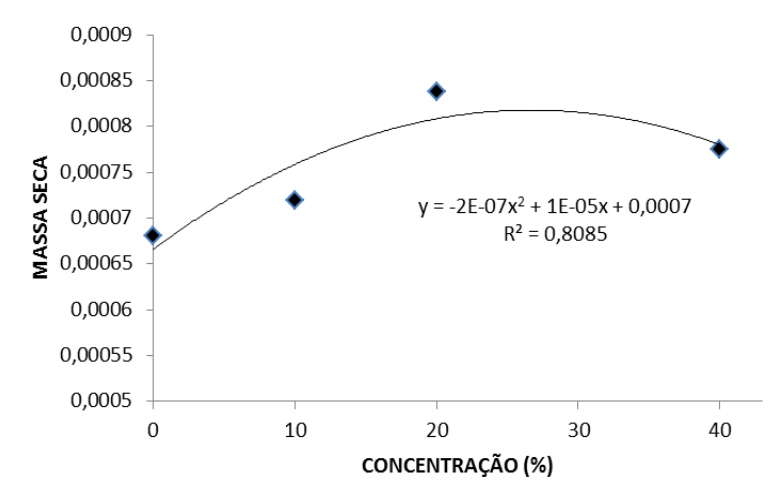

Figura 3. Massa de matéria seca de Lactuca sativa submetidas a diferentes doses de extrato aquoso de Croton glandulosus. Alta Floresta/MT, 2015. 
As partes da planta que mais provocaram redução no acúmulo de massa de matéria seca foram a do fruto e da raiz. Possivelmente estas partes acumularam quantidade maior de compostos aleloquímicos que promoveram a redução de massa de matéria seca de alface.

De maneira geral, a folha e a raiz são os órgãos da planta mais ativas metabolicamente. Possivelmente por esse motivo, estas apresentem maior diversidade e quantidade de aleloquímicos. Em seus estudos, JACOBI \& FERREIRA (1991) encontraram efeitos alelopáticos mais efetivos nos extratos de folhas de Mimosa bimucronata (DC). AIRES et al. (2005) trabalhando com Solanum lycocarpum L. também observaram resultados semelhantes.

Os resultados do presente trabalho indicam a presença de componentes aleloquímicos principalmente nas raízes e folhas de Croton glandulosus. Conforme EINHELLIG (1999), os efeitos alelopáticos resultam da ação de várias substâncias que atuam em conjunto. Em geral, os aleloquímicos são encontrados em baixas concentrações no meio ambiente.
Tabela 4. Biomassa de massa de matéria seca acumulada de plântulas de alface Lactuca sativa), submetidas à concentrações (p/v) de extratos de Croton glandulosus, utilizando água destilada. Alta Floresta MT, 2015.

\begin{tabular}{lc}
\hline Parte da planta & $\begin{array}{c}\text { Massa de matéria } \\
\text { seca }\end{array}$ \\
\hline Raiz & $0,000675 \mathrm{~b}$ \\
Caule & $0,000769 \mathrm{ab}$ \\
Folha & $0,000850 \mathrm{a}$ \\
Fruto & $0,000719 \mathrm{~b}$ \\
\hline & $\mathbf{1 5 , 8 0}$ \\
\hline *Médias seguidas de mesma letra na coluna não \\
diferem entre si pelo teste de Tukey a 5\% de \\
probabilidade.
\end{tabular}

\section{CONCLUSÃO}

De acordo com os resultados obtidos no presente estudo, pode-se concluir que Croton grandulosus L. apresenta potencial alelopático na raiz e na folha. Assim, a espécie pode servir de instrumento em manejos ecológicos, alternativo ao intenso uso de herbicidas.

\section{REFERÊNCIAS}

AIRES, S.S.; FERREIRA, A.G.;

BORGHETTI, F. Efeitos alelopáticos de folhas e frutos de Solanum lycocarpum A. St.Hil. (Solanaceae) na germinação e crescimento de Sesamum indicum L. (Pedaliaceae) em solo sob três temperaturas. Acta Botanica Brasilica, São Paulo, v.19, p.339-344, 2005.

BRASIL. Ministério da Agricultura. Regras para Análise de Sementes. Brasília-DF, 2009. 365p. 
CAPOBIANGO, R. A.; VESTENA, S.; BITTENCOURT, A. H. C. Alelopatia de Joanesia princeps Vell. e Casearia sylvestris Sw. sobre espécies cultivadas. Revista Brasileira de Farmacognosia, João Pessoa, v. 19, n. 4, p. 924-930, 2009.

DADKHAH, A.; ASAADI, A. M. Allelopathic effects of Eucalyptus camaldulensis on seed germination and growth seedlings of Acroptilon repens, Plantago lanceolata and Portulaca oleracea. Research of Journal Biologic

Sciences, v.5, n.6, p.430-434, 2010.

DE CONTI, D.; FRANCO, E.T.H. Efeito alelopático de extratos aquosos de Casearia sylvestris $\mathrm{Sw}$. na germinação e no crescimento de Lactuca sativa L. Revista Brasileira de Agrociência, Pelotas, v.17, n.24, p.193-203, 2011.

EINHELLIG, F. A. An integrated view of allelochemicals amid multiple stresses. In: INDERJIT; DAKSHINI, K. M. M.; FOY, C. L. (Ed.) Principles and practices in plant ecology. Boca Raton: CRC Press, p. 479494, 1999.

FERREIRA, A. G.; ÁQUILA, M. E. A. Alelopatia: uma área emergente da ecofisiologia. Revista Brasileira de Fisiologia Vegetal, Campinas, v.12, n. 1, p. 175-204, 2000.

FORMAGIO, A.S.N.; MASETTO, T.E.; VIEIRA, M.C.; ZÁRATE, N.A.H.; COSTA, W.F.; TREVIZAN, L.N.F.; SARRAGIOTTO, M.H. Potencial alelopático de Tropaeolum majus L. na germinação e crescimento inicial de plântulas de picão-preto. Ciência Rural, Santa Maria, v.42, n.1, p.83-89, 2012.

GONZALEZ, H.R. Efectos alelopáticos de restos de diferentes espécies de plantas medicinales sobre la albahaca (Ocimum basilicum L.) em condiciones de laboratório. Revista Cubana de Plantas Medicinales, Havana, v.7, n.2, p.67-72, 2002.
GRISI, P.U.; GUALTIERI, S.C.J.; Anese, S.; PEREIRA, V.C.; FORIM, M.R. Efeito do extrato etanólico de Serjania lethalis no controle de plantas daninhas. Planta Daninha, vol.31, n.2, p.239- 248, 2013.

JABRAN, K.; FAROOQ, M.; HUSSAIN, M.; ALI, M. Wild oat (Avena fatua) and canary grass (Phalaris minor Ritz.) management through allelopathy. Journal of Plant Protection, v.50, n.1, p.41-44, 2010.

JACOBI, U.S.; FERREIRA, A.G. Efeitos alelopáticos de Mimosa bimucronata (DC) O.K. sobre espécies cultivadas. Pesquisa Agropecuária Brasileira, Brasília, vol. 1, n.9, p.935-943, 1991.

KHALIQ, A.; MATLOOB, A.; KHAN, M.B.; TANVEER, A. Differential suppression of rice weeds by allelopathic plant aqueous extracts. Planta Daninha, v.31, n.1, p.2128, 2013.

KNOX, J.; JAGGI, D.; PAUL, M.S. Evaluation of allelopathic plant species on Parthenium hysterophorus. Egyptian Journal of Biology, Cairo, v.12, n.1, p.57-64, 2010.

MAGUIRE J.D. Speed of germination-aid in selection and evaluation for seedling emergence and vigor. Crop Science, Madison, v.2, n.1, p.176-177, 1962.

MOREIRA, H.J.C.;BRAGANÇA, H.B.N. "Manual de identificação de plantas infestantes: hortifruti." FMC Agricultural Products, São Paulo. 117p. 2011.

OLIVEIRA, A.K. de; DIÓGENES, F.E.P.; COELHO, M. de F.B.; MAIA, S.S.S.

Alelopatia em extratos de frutos de juazeiro (Ziziphus joazeiro Mart. Rhamnaceae). Acta Botanica Brasilica, São Paulo, v.23, n.4, p. 1186-1189, 2009.

OLIVEIRA, A.K.; COELHO, M.F.B.; MAIA, S.S.S.; DIÓGENES, F.E.P.; MEDEIROS FILHO, S. Alelopatia de extratos de diferentes órgãos de mulungu na germinação 
de alface. Horticultura Brasileira, Brasília, v.30, p.480-483, 2012.

PAULINO, V.T.; SCHUMANN, A.M.;

SILVA, S.C.; RASQUINHO, N.M.;

SANTOS, K.M. Impactos ambientais da exploração pecuária em sistemas intensivos de pastagem. Informe Agropecuário, Belo Horizonte, v.33, n.266, p.17-24, 2012.

REZENDE, G. A. A.; TERRONES, M. G. H.; REZENDE, D. M. L. C. Estudo do potencial alelopático do extrato metanólico de raiz e caule de Caryocar brasiliense Camb. (pequi). Bioscience Journal, Uberlândia, v. 27, n. 3, p. 460-472, 2011.

RITTER, M.C.; YAMASHITA, O.M.; CARVALHO, M.A.C. Efeito de extrato aquoso e metanólico de nim (Azadiracta indica) sobre a germinação de alface.

Multitemas, Campo Grande, v.1, n.46, p.0921, 2014.

RODRIGUES, A.P.D.C.; LAURA, V.A.; PEREIRA, S.R.; DEISS, C. Alelopatia de duas espécies de braquiária em sementes de três espécies de estilosantes. Ciência Rural, Santa Maria, v.42, n.10, p.1758-1763, 2012.

SILVEIRA, B.D.; HOSOKAWA, R.T.; NOGUEIRA, A.C.; WEBER, V.P. Atividade alelopática de Araucaria angustifilia (Bertol.) Kuntze na germinação e crescimento inicial de Lactuca sativa L. Ciência Florestal, Santa Maria, v.24, n.1, p.79-85, 2014.

VENDRAME, G.H.M.; YAMASHITA, O.M.; CARVALHO, M.A.C.; CAMPOS, O.R.; DALLACORT, R.; KOGA, P.S.; PARENTE, T.L.; CAIONI, S.; PERES, W.M.;OLIVEIRA, R.B. Manejo químico de Vismia guianensis com diferentes misturas de herbicidas auxínicos em área de pastagem de Brachiaria brizantha. Revista de Ciências Agroambientais, Alta Floresta, v.12, n.1, p.35-41, 2014. 